\title{
Morfometria e análise populacional de colônias de Apoica flavissima (Hymenoptera, Vespidae) coletadas na Amazônia brasileira
}

\author{
Thiago ELISEI ${ }^{1}$, Juliana Vaz e NUNES ${ }^{1}$,Jacó Rocha da SILVA ${ }^{1}$, Francinilda de Castro MACIEL ${ }^{1}$
}

\begin{abstract}
RESUMO
Duas colônias da vespa social Apoica flavissima foram coletadas e analisadas quanto aos parâmetros morfométricos e a população residente no ninho. Estas estavam fundadas a cerca de $700 \mathrm{~mm}$ do chão, nidificadas em plantas herbáceas, nas proximidades de igarapés. Ambas se encontravam no inicio do seu ciclo biológico e apresentavam um pequeno número de indivíduos, quando comparado com outros trabalhos com este gênero. Os adultos foram mensurados com médias de 21,62 mm de comprimento do corpo; 3,8 $\mathrm{mm}$ de largura máxima do tórax e 3,5 mm de largura da cabeça. As pupas apresentaram 20,05 mm de comprimento corpóreo; $3,75 \mathrm{~mm}$ de largura máxima do tórax e 3,51 $\mathrm{mm}$ de largura da cabeça. Ambientes naturais devem favorecer o crescimento dos indivíduos assim como manter os seus padrões de nidificação. Assim, uma discrepante taxa de crescimento e diferentes hábitos de nidificação, podem indicar a influência do ambiente sobre a biologia deste grupo.
\end{abstract}

PALAVRAS CHAVES: Vespa social, Bioindicador, Biologia de vespas, Amazônia

\section{Morphometric and population analysis of colonies of the Apoica flavissima (Hymenoptera, Vespidae) collected in Brazilian Amazonia}

\begin{abstract}
Two colonies of the social wasp Apoica flavissima were collected and analyzed to verify the population and morphometric averages of the individuals. Both colonies were in bushes at $700 \mathrm{~mm}$ above the floor, close to forest creeks. The colonies were at the beginning of their development stage and showed a reduced number of individuals, when compared with other studies on this genus. Means of adult parameters were: body length $21,6 \mathrm{~mm}$; width of thorax 3,8 $\mathrm{mm}$; and width of head, $3,5 \mathrm{~mm}$ . Pupae presented these averages: body length $20,05 \mathrm{~mm}$; width of thorax $3,75 \mathrm{~mm}$; and width of head $3,51 \mathrm{~mm}$. Natural environment must offer good conditions for the development of wasps and their pattern nesting. Thus, high growth rates and different nesting behavior can demonstrate environmental influences on biology of this wasp group.
\end{abstract}

KEYWORDS: Social wasp, wasp biology, bioindicators, Rain forest.

1 Emails: thiagoelisei@yahoo.com.br, juvazenues@yahoo.com.br, jaco_rocha@hotmail.com, nildamacielbio@globomail.com. Universidade do Estado do Amazonas - Centro de Estudos Superiores de Tefé. Estrada do Bexiga, $n^{0}$ 1085, Jerusalém, Tefé, AM. 


\section{INTRODUÇÃO}

Apoica se destaca por apresentar o hábito de forragear no período noturno, diferentemente de outras espécies dos outros gêneros de vespas sociais (Nascimento e Tannure-Nascimento 2005). Seus ninhos são compostos por um único favo descoberto e são construídos diretamente sobre o substrato, não apresentando pedúnculo (Carpenter e Marques, 2001). São poucos os trabalhos com espécies deste gênero, podendo se destacar estudos de emigração (Ducke 1905, Schremmer 1972, Hunt et al. 1995, Howard et al. 2003) comportamento de nidificação (Vecht 1972), castas (Shima et al. 1994, Jeanne 1995, Nascimento et al. 2003) e história natural (Hunt et al. 1995).

Este grupo utiliza como habitat áreas de mata com certa preservaçáo, podendo ser utilizado como bioindicador de qualidade ambiental. A bioindicação pode ser evidenciada por estes himenópteros uma vez que algumas espécies podem ser prejudicadas durante o desmatamento e outras favorecidas em ambientes antropofizados, desmatados ou em processo de sucessão secundária da vegetação (Morato 2001). O objetivo deste trabalho foi conhecer a biologia do grupo através da análise morfométrica e populacional de colônias de Apoica flavissima.

\section{MATERIAL E MÉTODOS}

Duas colônias de $A$. flavissima foram coletadas, ambas em épocas de seca na regiáo amazônica, no período da manhá, com sol intenso, momento no qual a espécie apresenta baixa atividade, minimizando o risco de perda de indivíduos coletados. As colônias foram retiradas da Reserva Flora Agrícola Agrovila (colônia A) e da Floresta Nacional de Tefé (colônia B), áreas estas compostas por mata nativa e baixo grau de antropofização, localizadas no município de Tefé, AM.

A triagem do material foi realizada no Laboratório de Biologia do Centro de Estudos Superiores de Tefé/Universidade do Estado do Amazonas, localizado no município de Tefé, AM. Os ovos, larvas, pupas e adultos foram quantificados e amostras de indivíduos adultos e de pupas foram mensuradas, quanto

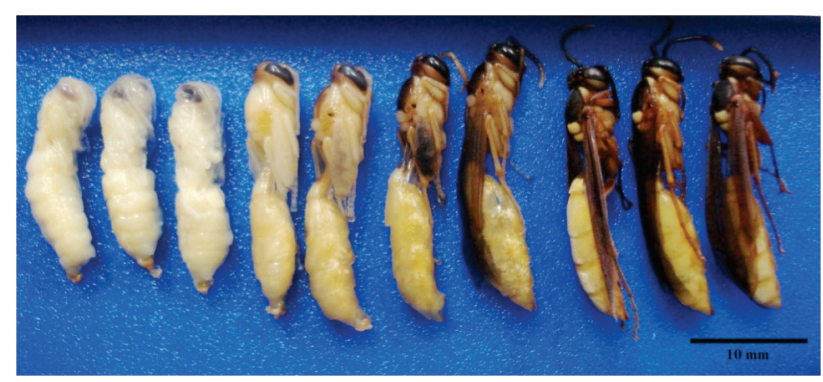

Figura 1- Pupas e indivíduos adultos de Apoica flavissima analisados quanto a seus parâmetros morfométricos, oriundos de duas colônias coletadas no município de Tefé, AM ao comprimento do corpo, larguras máximas do tórax e da cabeça, a fim de caracterizar estes parâmetros biológicos. Todas as medidas foram realizadas através de paquímetro manual com precisão de $0.05 \mathrm{~mm}$. Foi utilizado o teste $t$-student para verificar possíveis diferenças significativas entre os parâmetros morfométricos das duas populaçóes de adultos das colônias analisadas $(\mathrm{p}<0,05)$.

\section{RESULTADOS E DISCUSSÃO}

As duas colônias se encontravam a cerca de $700 \mathrm{~mm}$ do chão (750 mm a colônia A e $680 \mathrm{~mm}$ a colônia B), nidificadas em plantas herbáceas, nas proximidades de igarapés, fato comum nas espécies deste gênero que escolhem sempre as adjacências de recurso hídricos como locais de fundação. $\mathrm{O}$ fato de estar em ambientes naturais, pouco antropofizados, proporciona a este grupo fundar seus ninhos em baixas alturas. Isto porque em ambientes impactados, as vespas tendem a fundar suas colônias acima dos três metros, dificultando as injúrias causadas pelos humanos (Lima et al. 2000).

Algumas espécies de vespa social armazenam mel e presas abatidas em seus ninhos (Hunt et al. 2003; Prezoto e Gobbi 2003), no entanto, estes recursos não foram encontrados nos ninhos de $A$. flavissima analisados.

O ninho da colônia A continha 364 células e apresentou as seguintes medidas máximas: $76 \mathrm{~mm}$ de comprimento, 64 $\mathrm{mm}$ de largura e $36 \mathrm{~mm}$ de altura, formando um hexágono, comportamento de nidificação já descrito para a espécie por Carpenter e Marques (2001). Foram encontrados 48 ovos e 30 larvas, todas elas de tamanho reduzido, estando entre o primeiro e terceiro instares. No total os adultos foram 201 indivíduos, além disso, foram encontradas 52 pupas, não havendo pré-pupas em desenvolvimento no ninho.

O ninho da colônia B apresentou 125 células com $41 \mathrm{~mm}$ de comprimento, 42,4 $\mathrm{mm}$ de largura e 27,6 mm de altura. Foram encontrados 26 adultos, seis pupas, duas larvas e seis ovos, revelando um menor tempo de fundação desta colônia quando comparada à colônia $\mathrm{A}$. Esta evidência esta no fato de este grupo de vespas fundar seus ninhos a partir de poucos ou apenas uma rainha, que constrói as primeiras células e inicia o ciclo de expansão da colônia (Carpenter e Marques 2001).

As colônias desta espécie podem apresentar grandes dimensóes, como citado por Yamane et al (2009), que estudou um ninho com largura de $290 \mathrm{~mm}$ e $265 \mathrm{~mm}$ de comprimento, contendo 3.000 células, 586 ovos, 887 larvas e 1.272 pupas. Sendo assim, as duas colônias estudadas poderiam estar no início de desenvolvimento, fato corroborado pela ausência de machos, que emergem apenas no final do ciclo biológico das colônias (Jeanne 1972). Isto pode estar relacionado com os pulsos de inundaçóes da Amazônia, uma vez que ambas as colônias foram coletadas em períodos de seca, marcados pela 
Tabela 1 - Parâmetros Morfométricos (Média \pm DP mm) e Teste T-Student $(p<0,05)$ sobre as medidas dos adultos e pupas presentes em duas colônias de Apoica flavissima, coletadas em Tefé, AM. (C.C. = comprimento corpóreo, L.T. = largura do tórax; L.C. $=$ largura da cabeça).

\begin{tabular}{lcccc}
\hline & COLÔNIA A & COLÔNIA B & MÉDIA $(\mathrm{A}+\mathrm{B})$ & $\begin{array}{c}\text { Teste } t \\
(\mathrm{~A} / \mathrm{B})\end{array}$ \\
\hline ADULTOS & & & & \\
\hline C.C & $22,74 \pm 0,6$ & $19,61 \pm 1,82$ & $21,62 \pm 2,5$ & $\mathrm{p}<0,0001$ \\
L.T. & $3,86 \pm 0,46$ & $3,33 \pm 0,1$ & $3,8 \pm 0,4$ & $\mathrm{p}=0,0003$ \\
L.C. & $3,71 \pm 0,47$ & $3,63 \pm 0,1$ & $3,5 \pm 0,4$ & $\mathrm{p}=0,048$ \\
\hline PUPAS & & & & \\
\hline C.C & $21,01 \pm 2,27$ & $19,22 \pm 1,76$ & $20,05 \pm 2,1$ & $\mathrm{p}<0,03$ \\
L.T. & $4,10 \pm 0,33$ & $3,41 \pm 0,24$ & $3,75 \pm 0,43$ & $\mathrm{p}<0,002$ \\
L.C. & $3,78 \pm 0,22$ & $3,42 \pm 0,57$ & $3,51 \pm 0,21$ & $\mathrm{p}=0,041$ \\
\hline
\end{tabular}

quedas na oferta de alimentos, não sendo uma época favorável para o desenvolvimento das vespas (Jeanne 1991).

Os adultos, analisando todos os coletados nas duas colônias ( $\mathrm{n}=227$ ), apresentaram $21,62 \mathrm{~mm}$ de tamanho médio de comprimento corpóreo (Tabela 1). A espécie apresenta porte avantajado quando relacionada com outras de outros gêneros de vespas sociais (Machado et al. 1988; Carpenter e Marques 2001). Isto pode ser a causa do grande temor que o grupo causa nos moradores de áreas próximas às suas colônias, o que acaba resultando em injúrias aos himenópteros por parte dos humanos.

As populaçôes de adultos das duas colônias apresentaram diferenças significativas quanto as suas medidas (Tabela 1). Esta diferença pode revelar um padrão no qual as colônias mais bem estabelecidas no ambiente, com mais tempo de fundação, tendem a desenvolver operárias mais bem desenvolvidas. $\mathrm{O}$ fato pode ser ilustrado pela média superior dos indivíduos da colônia $\mathrm{A}$, os quais se encontravam em maior número $\mathrm{e}$ apresentaram maior porte (Tabela 1). A supracitada colônia também apresentou as pupas de maiores tamanhos. No entanto, o reduzido número destes indivíduos na colônia $\mathrm{B}$ faz com os valores do teste para verificar a significância destas variaçóes não sejam confiáveis (Tabela 1).

Embora haja diferenças entre as dimensôes dos adultos analisados das colônias, a morfometria dos indivíduos de A. flavissima pode revelar que tamanhos discrepantes aos encontrados no presente trabalho, indicariam alguma alteração do ambiente. O desenvolvimento de adultos de maior porte poderia estar ligado a uma maior oferta de presas, principal alimento dos imaturos que se desenvolvem na colônia, que em mais de $90 \%$ são oriundas da captura de lagartas desfolhadoras (Raveret Richter 2001, Elisei et al 2010). Assim, um maior desenvolvimento dos indivíduos, pode ser resultado do impacto da presença destes imaturos de lepidópteros, devido ao cultivo de monoculturas nas proximidades das colônias (Altieri 2003). Da mesma forma, a reduçáo no porte dos indivíduos pode ser devido à uma queda na oferta de alimento nas áreas exploradas pelas forrageadoras, podendo indicar alguma alteração ambiental. Isto pode ocorrer em supressôes de mata, por exemplo, levando assim a uma queda nos recursos de forrageio e redução no desenvolvimento das pupas e conseqüentemente também dos adultos.

O desenvolvimento da colônia e de todos os indivíduos que a compóem é resultado de uma intensa interação com ambiente. Ambientes naturais devem favorecer o crescimento dos indivíduos assim como manter os seus padróes comportamentais, como por exemplo, padróes de nidificação. Deste modo, uma discrepante taxa de crescimento e diferentes hábitos de nidificação, podem indicar a influência do ambiente sobre a biologia de diferentes grupos de vespas sociais.

\section{CONCLUSÃO}

O estudo de vespas sociais, como análises populacionais e morfométricas, gera informaçôes relevantes quanto à aplicação do grupo como indicador de qualidade ambiental. Os resultados do presente trabalho podem ser parâmetros importantes para futuras comparaçōes em diferentes áreas nas quais colônias de $A$. flavissima possam vir a ser avaliadas.

\section{REFERÊNCIAS BIBLIOGRÁFICAS}

Altieri, A.M.; Silva, E.N.; Nicholls, C.I. 2003. O papel da biodiversidade no manejo de pragas. $1^{\text {a }} \mathrm{Ed}$, Editora Holos, $226 \mathrm{pp}$.

Carpenter, J.M.; Marques, O.M. 2001. Contribuição ao estudo dos vespídeos do Brasil (Insecta: Hymenoptera, Vespoidae, Vespidae). Cruz das Almas, Universidade Federal da Bahia. Publicaçôes digitais, Volume 2. Universidade Federal da Bahia.

Ducke, A. 1905. Sobre as vespidas sociaes do Pará (Supplemento I). Boletim do Museu Goeldi, 4: 652-698.

Elisei, T.; Nunes, J. V.; Ribeiro Junior, C.; Fernandes Junior, A. J.; Prezoto, F. 2010. Uso da vespa social Polistes versicolor no controle de desfolhadores de eucalipto. Pesquisa Agropecuária Brasileira, 45:958-964.

Raveret Richter, M. 2000. Social wasp (Hymenoptera: Vespidae) foraging behavior. Annual Review of Entomology. 45:121-150.

Hunt, J.H.; Jeanne, R.L.; Keeping, M.B. 1995. Observations on Apoica pallens, a nocturnal Neotropical social wasp (Hymenoptera: Vespidae, Polistinae, Epiponini). Insectes Sociaux, 42: 223-236.

Hunt, J. H.; Buck, N. A.; Wheeler, D. E. 2003. Storage proteins in vespid wasps: characterization, developmental pattern and occurrence in adults. Journal of Insect Physiology, 49: 785-794.

Howard, K.J.; Smith, A.R.; O’Donnell, S. ; Jeanne, R.L.. 2002. Novel method of swarm emigration by the epiponine wasp, Apoica pallens (Hymenoptera Vespidae). Ethology Ecology \& Evolution, 14: 365-371.

Jeanne, R.L. 1972. Social biology of the neotropical wasp Mischocytarus drewseni. Bulletim of the Museum of Comparative Zoology. 144(3): 63-150. 
Jeanne, R. L. The swarm-founding Polistinae. In: ROSS, K. G., MATTHEWS, R. W. (eds.). The Social Biology of Wasps. Ithaca: Comell University Press, 1991. p. 191-231.

Jeanne, R.L.; Hunt, J.H. ; Keeping, M.G. 1995. Foraging in social wasps: Agelaia lacks recruitment to food (Hymenoptera: Vespidae). Journal of the Kansas Entomological Society, 68: 279-289.

Lima, M.A.P.; Lima, J.R. ; Prezoto, F. 2000. Levantamento dos gêneros, flutuação das colônias e hábitos de nidificação de vespas sociais (Hymenoptera, Vespidae), no campus da UFJF, Juiz de Fora, MG. Revista Brasileira de Zoociências, 2(1): 69-80.

Machado, V.L.L.; Graven, S.; Giannotti, E. 1988. Análise populacional e morfométrica de uma colônia de Brachygastra lecheguana (Latreille, 1824)) na fase reprodutiva. Anais da Sociedade Entomológica do Brasil, 17 (2): 491-506.

Morato, E. F. 2001 Efeitos da fragmentação florestal sobre vespas e abelhas solitárias na Amazônia Central. Revista Brasileira de Zoologia, 18 (3): 101-118.

Nascimento, F.S.; Tannure-Nascimento, I.C.; Raposo-Filho, J.R. 2003. Population dynamics of the Neotropical swarm-founding wasp Apoica flavissima (Hymenoptera: Vespidae: Epiponini), with emphasis on caste dimorphism. Sociobiology. 41: 689-698.
Nascimento, F.S.; Tannure-Nascimento, I.C.2005. Foraging patterns in a nocturnal swarm-founding wasp, Apoica flavissima Van der Vecht (Hymenoptera: Vespidae). Neotropical Entomology. 34(2):177-181

Prezoto, F.; Gobbi, N. 2003. Patterns of honey storage in nests of the Neotropical paper wasp Polistes simillimus Zikán, 1951 (Hymenoptera, Vespidae). Sociobiology, 41: 437-442.

Schremmer, F. 1972. Beobachtungen zur Biologie von Apoica pallida (Olivier, 1791), einer neotropischen sozialen Faltenwespe (Hymenoptera: Vespidae). Insectes Sociaux, 19: 343-357.

Shima, S.N.; Yamane, S.; Zucchi, R. 1994. Morphological caste differences in some neotropical swarm-founding polistine wasps I: Apoica flavissima (Hymenoptera, Vespidae). Japan Journal Entomology, 62: 811-822.

Vecht, J. Van Der. 1972. The social wasps (Vespidae) collected in French Guyana by the mission du Muséum National d'Historie Naturelle with notes on the genus Apoica Epeletier. Annales de la Société Entomologique de France, 8: 735-743.

Yamane, S.; Mateus, S.; Hozumi, S.; Kudô, K.; Zucchi, R. 2009. How does a colony of Apoica flavissima (Hymenoptera: Vespidae, Epiponini) maintain a constant temperature? Entomological Science, 12, 341-345.

Recebido em :15/12/2011

Aceito em: 03/05/2012 